\title{
Cocaine-Induced Behavioral Sensitization: Effects of Haloperidol and SCH 23390 Treatments
}

\author{
BRUCE A. MATTINGLY,' JAMES K. ROWLETT, ${ }^{2}$ TRACEY ELLISON AND KRISTIN RASE
}

Department of Psychology, Morehead State University, Morehead, KY 40351-1689

Received 20 April 1995; Revised 24 July 1995; Accepted 9 August 1995

\begin{abstract}
MATTINGLY, B. A., J. K. ROWLETT, T. ELLISON AND K. RASE. Cocaine-induced behavioral sensitization: Effects of haloperidol and SCH 23390 treatments. PHARMACOL BIOCHEM BEHAV 53(3) 481-486, 1996. - The objective of this study was to determine whether the development of behavioral sensitization to cocaine could be prevented by high doses of the dopamine receptor antagonists haloperidol and SCH 23390. In two experiments, male Wistar rats were injected daily for 4 days with either cocaine $(15 \mathrm{mg} / \mathrm{kg}$, IP) or vehicle in combination with haloperidol $(1.0 \mathrm{mg} / \mathrm{kg}, \mathrm{IP}), \mathrm{SCH} 23390$ $(0.5 \mathrm{mg} / \mathrm{kg}, \mathrm{SC})$, or vehicle. After the daily injections, the rats were tested for locomotor activity in photocell arenas. At $24 \mathrm{~h}$ after the last preexposure test session, all rats were given a challenge injection of cocaine ( $15 \mathrm{mg} / \mathrm{kg}$, IP) and tested for activity. Cocaine treatments produced a greater relative increase in locomotor activity with repeated exposure compared to vehicle treatments (i.e., sensitization). Moreover, the acute activating effects of cocaine over days were blocked by both haloperidol and SCH 23390. The coadministration of haloperidol, but not SCH 23390 , blocked the development of behavioral sensitization to cocaine. That is, after the cocaine challenge injection, rats pretreated with SCH 23390 and cocaine did not differ from rats preexposed only to cocaine, whereas rats pretreated with haloperidol and cocaine did not differ from rats pretreated only with vehicle. Pretreatment with haloperidol or SCH 23390 without cocaine enhanced the locomotor-activating effects of the subsequent cocaine challenge injection. These findings suggest that cocaine-induced behavioral sensitization may develop as a result of repeated dopamine $D_{1}-$ or $D_{2}$-type receptor stimulation, and that brief dopamine antagonist treatments enhance subsequent behavioral sensitivity to cocaine.
\end{abstract}

Dopamine antagonists $\quad D_{1}$ receptors $\quad D_{2}$ receptors $\quad$ Stimulants $\quad$ Dopamine agonists Locomotor activity

THE REPEATED administration of both direct (e.g., apomorphine) and indirect (e.g., cocaine, amphetamine) dopamine receptor agonists in rodents results in the development of behavioral sensitization [e.g., $(14,21,30)$ ]. This sensitization effect is characterized by a progressive augmentation in various drug-induced motor behaviors and appears to be mediated by both pre- and postsynaptic mechanisms in mesolimbic and/ or nigrostriatal dopamine systems [see $(11,13,28,29)$ for reviews].

Although most dopamine agonists that induce behavioral sensitization result in an increased stimulation of both dopamine $D_{1}$ - and $D_{2}$-receptor subtypes, recent evidence suggests that the dopamine $D_{1}$-receptor subtype plays a critical role in the development of behavioral sensitization. The development of behavioral sensitization to amphetamine, for example, is prevented by the coadministration of the selective $D_{1}$-receptor antagonist SCH 23390 , injected either systemically or directly into the ventral tegmental area $(7,30,34)$. In contrast, coadministration of $\mathrm{D}_{2}$-dopamine receptor antagonists metoclopramide, pimozide, sulpiride, or RO-22-2586, does not block the development of behavioral sensitization to amphetamine $(7,34)$. Likewise, the development of behavioral sensitization to the direct $D_{1} / D_{2}$-dopamine receptor agonist apomorphine is also prevented by the coadministration of dopamine $D_{1}$ - but not $\mathrm{D}_{2}$-receptor antagonists (21). Moreover, recent evidence indicates that the development of behavioral sensitization to the selective dopamine $D_{2}$-type receptor agonists bromocryptine and quinpirole is blocked by the coadministration of the

\footnotetext{
'To whom requests for reprints should be addressed. E-mail: b.mattin@msuacad.morehead-st-edu.

2 Dr. Rowlett's current address is Department of Psychiatry and Human Behavior, Arthur C. Guyton Laboratory Research Building, The University of Mississippi Medical Center, 2500 North State Street, Jackson, MS 39216-4505.
} 
dopamine $\mathrm{D}_{1}$-type antagonist SCH $23390(22,36)$. Thus, dopamine $D_{1}$-receptor stimulation appears to be necessary for the induction of behavioral sensitization to both direct and indirect dopamine agonists.

Like amphetamine- and apomorphine-induced behavioral sensitization, the development of behavioral sensitization to the locomotor-activating effects of cocaine is thought to involve the stimulation of dopamine receptors [e.g., $(4,10,15$, $25,32)]$. Recent evidence, however, indicates that the coadministration of selective $\mathrm{D}_{1}$-type (SCH 23390) or $\mathrm{D}_{2}$-type (sulpiride, YM-09151-2) antagonists does not prevent the development of behavioral sensitization to cocaine $(16,19)$. These findings suggest the possibility that cocaine-induced behavioral sensitization, unlike amphetamine-induced sensitization, may develop as a result of stimulation of either dopamine receptor subtype or through some nondopaminergic mechanism.

\section{EXPERIMENT 1}

Although low doses of the mixed $\mathrm{D}_{1} / \mathrm{D}_{2}$-dopamine antagonist haloperidol have been reported not to block the expression of cocaine-induced behavioral sensitization $(18,35)$ or the development of cocaine-induced conditioned hyperactivity (27), higher doses of haloperidol have been reported to block the development of behavioral sensitization to cocaine in a 2-day conditioning paradigm $(9,35)$.

The purpose of Experiment 1 was to determine whether the coadministration of a high dose of haloperidol with cocaine would prevent the development of behavioral sensitization in a repeated-treatment sensitization paradigm.

\section{Method}

Subjects. A total of 47 male Wistar albino rats (Harlan Sprague-Dawley, Indianapolis, IN), weighing between 250 and $350 \mathrm{~g}$, served as subjects. All rats were housed individually in hanging wire mesh cages in a colony room with a $12 \mathrm{~L}$ : $12 \mathrm{D}$ cycle and food and water available continuously. All behavioral testing was conducted during the light phase of the cycle.

Apparatus. Activity measures were taken in two BRS/LVE cylindrical activity drums (Model 145-03; Beltsville, MD). The floor of each drum was $60 \mathrm{~cm}$ in diameter and was made of diamond-shaped wire mesh. The interior wall of each drum was $43 \mathrm{~cm}$ high and painted flat black. Each drum was located in a sound-attenuated experimental cubicle that was kept dark during testing.

Two banks of three infrared photocells were mounted on the outside of the drum. The six photocell beams were approximately $12 \mathrm{~cm}$ apart arranged in a criss-cross pattern $2.5 \mathrm{~cm}$ above the floor of the drum. The photocell banks were connected to back-path eliminator diodes. Movement of the rat through a photocell beam sent a single pulse to the counters. Pulses spaced $<0.5 \mathrm{~s}$ apart were recorded as a single count by this method.

Drugs. Cocaine hydrochloride (Sigma, St. Louis, MO) was dissolved daily into distilled $\mathrm{H}_{2} \mathrm{O}$. Haloperidol (Sigma) was mixed daily in a $1 \%$ lactic acid solution. All injections were IP in a volume of $1.0 \mathrm{ml} / \mathrm{kg}$. Control injections were given using the appropriate vehicle using the same route and volume as the corresponding drug injection. All doses were calculated based on the salt weight of the drug.

Procedures. At the beginning of testing, the rats were randomly assigned to one of four groups ( $n$ 's $=11-12$ /group) comprising the two (vehicle or haloperidol) $\times$ two (vehicle or cocaine) factorial design. On each day of the preexposure phase of the experiment, each rat was first injected with either vehicle or haloperidol $(1.0 \mathrm{mg} / \mathrm{kg})$ and then, $30 \mathrm{~min}$ later, injected with either vehicle or cocaine $(15 \mathrm{mg} / \mathrm{kg})$. Five minutes after this second injection, each rat was placed into the activity drum and activity was recorded for $20 \mathrm{~min}$. This injection-test procedure was repeated daily for 4 days. Sensitization testing was conducted $24 \mathrm{~h}$ after the last preexposure test. On this test day, all rats were given a challenge injection of cocaine $(15 \mathrm{mg} / \mathrm{kg})$ and then tested for activity $5 \mathrm{~min}$ later.

Data analysis. Significant differences among the groups in mean activity counts during the preexposure sessions were determined with three-factor mixed analyses of variance (ANOVA) using haloperidol and cocaine treatments as between-group factors and daily test session as a repeated measure. The cocaine challenge test data were analyzed with a two-factor ANOVA. Significant interactions were evaluated with additional ANOVA's followed by $t$-tests or NeumanKeuls post hoc tests.

\section{Results}

Preexposure days 1-4. The mean activity counts of the four groups on the 4 preexposure days are shown in Fig. 1. Haloperidol produced a marked decrease in locomotor activity on each test day [haloperidol effect: $F(1,43)=185.29$, $p<0.0001]$. Overall, cocaine produced an increase in activity [cocaine effect: $F(1,43)=33.51, p<0.0001$, but this increase was greater for rats pretreated with vehicle than for those pretreated with haloperidol [Haloperidol $\times$ Cocaine interaction, $F(1,43)=14.93, p<0.0005]$. Moreover, for rats pretreated with vehicle, cocaine injections produced a greater increase in locomotor activity compared to vehicle injections on preexposure day 4 than on day 1 [Cocaine $\times$ Session interaction: $F(3,29)=13.26, p<0.05$; Haloperidol $\times$ Cocaine $\times$ Session interaction: $F(3,129)=2.84, p<0.05$ ].

Cocaine challenge test. The mean activity counts for the four preexposure groups following a challenge injection of cocaine are shown in Fig. 2. The ANOVA performed on these

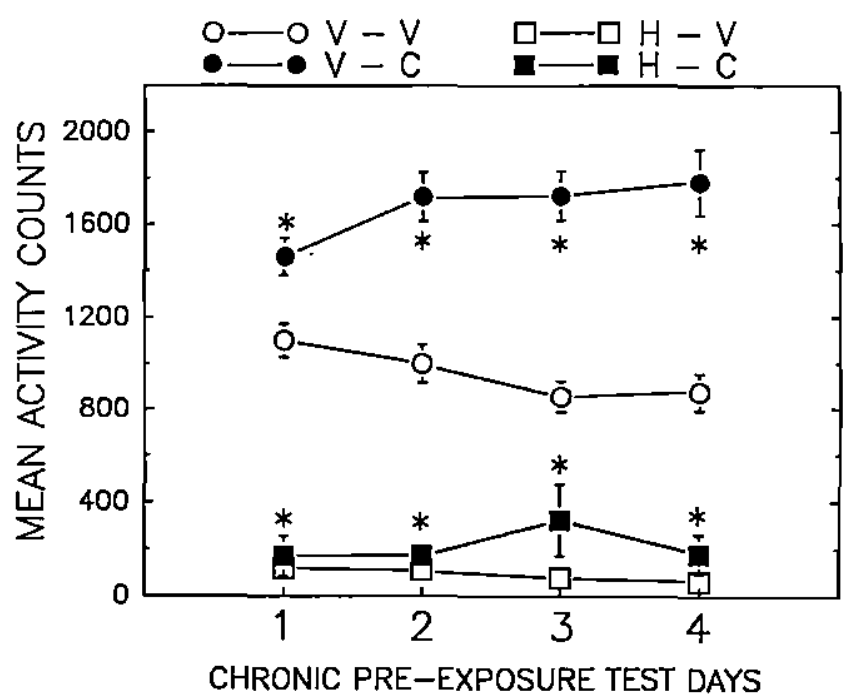

FIG. 1. Mean activity counts ( \pm SEM) per 20 -min session across the 4. preexposure days for rats injected daily with either vehicle (V) or 1.0 $\mathrm{mg} / \mathrm{kg}$ haloperidol $(\mathrm{H})$ followed by either vehicle or $15 \mathrm{mg} / \mathrm{kg}$ cocaine (C): ${ }^{*} p<0.05$ compared to V-V group. 


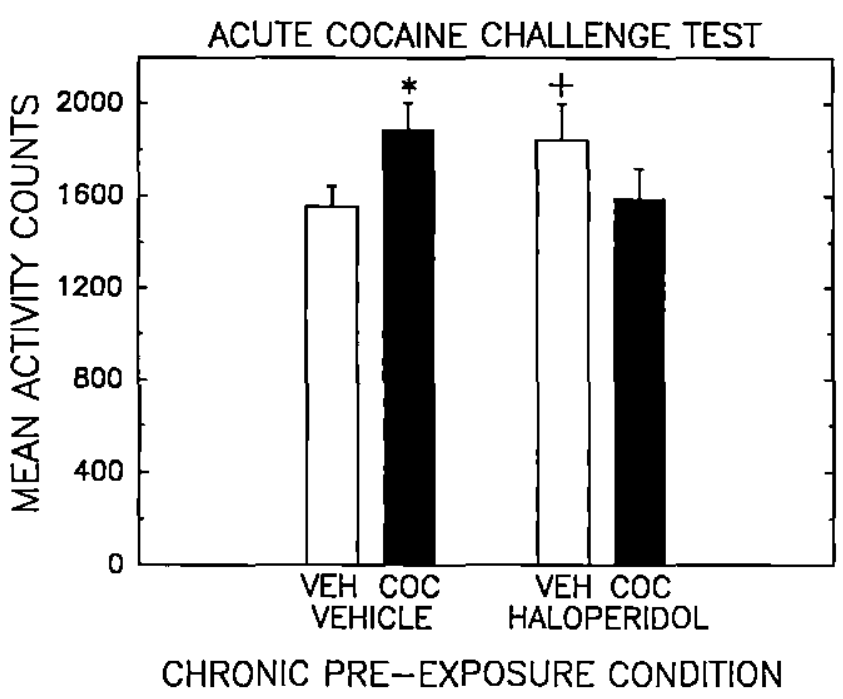

FIG. 2. Mean activity counts ( \pm SEM) per 20-min session following a challenge injection of cocaine $(15 \mathrm{mg} / \mathrm{kg}$ ) for groups of rats previously treated daily with either vehicle or $1.0 \mathrm{mg} / \mathrm{kg}$ haloperidol and either vehicle (VEH) or $15 \mathrm{mg} / \mathrm{kg}$ cocaine (COC) for 4 days. ${ }^{*} p<0.05$ compared to VEHICLE-VEH group. ${ }^{+} p<0.06$ compared to VEHICLE-VEH group.

data revealed a main effect of neither haloperidol nor cocaine pretreatment ( $p$ 's $>0.05$ ); however, the Haloperidol $\times$ Cocaine pretreatment interaction was significant $[F(1,43)=5.48$, $p<0.03$ ]. Subsequent analysis of this interaction indicated that the challenge injection of cocaine produced significantly greater activity in rats previously treated with vehicle and cocaine for 4 days than for rats pretreated with only vehicle $(p<0.05)$. In contrast, the cocaine-induced activity of rats previously treated with haloperidol and cocaine for 4 days did not significantly differ from that of the vehicle-vehicle-pretreated rats $(p>$ 0.05 ). In other words, the coadministration of haloperidol with cocaine for 4 days blocked the development of sensitization to cocaine. Moreover, the challenge injection of cocaine produced a greater activity increase in rats previously given haloperidol and vehicle compared to rats previously given only vehicle injections $(p<0.06)$.

\section{EXPERIMENT 2}

The results of Experiment 1 indicate that haloperidol treatments blocked the acute locomotor activating effects of cocaine over days, as well as the development of behavioral sensitization. Although haloperidol has greater affinity for dopamine $D_{2}$ than $D_{1}$ receptors, the fact that selective dopamine $\mathrm{D}_{1}$ - or $\mathrm{D}_{2}$-receptor antagonists do not block behavioral sensitization to cocaine $(16,19)$ suggests that the relatively high dose of haloperidol used in the present study may have blocked sensitization to cocaine as a result of blocking both $D_{1}$-and $D_{2}$-receptor subtypes.

Although haloperidol treatments blocked the development of sensitization to cocaine, repeated haloperidol treatments alone resulted in an enhanced locomotor response to the subsequent cocaine challenge injection. In our previous study (19), a similar but not significant enhancement in cocaine sensitivity was observed following repeated sulpiride or SCH 23390 treatments. Moreover, Kuribara and Uchihashi (16) reported that the coadministration of SCH 23390 or YM-
09151-2 with cocaine enhanced the activating effects of a subsequent cocaine challenge injection. These investigators, however, did not include an antagonist-only control group during preexposure.

Although we used a relatively high dose $(0.3 \mathrm{mg} / \mathrm{kg})$ of SCH 23390 in our previous study (19), we decided to partially replicate this experiment using a higher dose of SCH 23390 to determine: a) whether a high dose of SCH 23390 , like haloperidol, would block the development of behavioral sensitization to cocaine; and b) whether a repeated high dose of SCH 23390 would significantly increase subsequent sensitivity to cocaine. Experiment 2 was therefore the same as Experiment 1, except $\mathrm{SCH} 23390(0.5 \mathrm{mg} / \mathrm{kg})$, rather than haloperidol, was used.

\section{Method}

Subjects and procedure. Sixty male Wistar albino rats (Harlan Sprague-Dawley), weighing between 250 and $350 \mathrm{~g}$, were randomly assigned in equal numbers to one of four groups comprising the 2 (SCH 23390 vs. vehicle) $\times 2$ (cocaine vs. vehicle) factorial design. SCH 23390 (Research Biochemicals) was dissolved in distilled $\mathrm{H}_{2} \mathrm{O}$ and injected $\mathrm{SC}$. The apparatus and procedure was the same as in Experiment 1.

\section{Results}

Preexposure days 1-4. The mean activity counts of the four groups across the four preexposure test days are shown in Fig. 3. The $0.5-\mathrm{mg} / \mathrm{kg}$ dose of $\mathrm{SCH} 23390$ produced a significant decrease in locomotor activity on each test day [SCH 23390 effect: $F(1,56)=531.32, p<0.0001$ ]. Overall, cocaine produced an increase in activity [cocaine effect: $F(1$, 56) $=44.30, p<0.0001]$, but this increase was greater for rats pretreated with vehicle than for those pretreated with SCH 23390 [SCH $23390 \times$ Cocaine interaction, $F(1,56)=$ 28.41, $p<0.0001]$. Moreover, the cocaine-induced increase in activity, relative to vehicle treatment, was greater for the vehicle pretreatment group on day 4 than on day 1 [Cocaine $\times$ Session interaction: $F(3,168)=12.16, p<0.0001 ; \mathrm{SCH}$

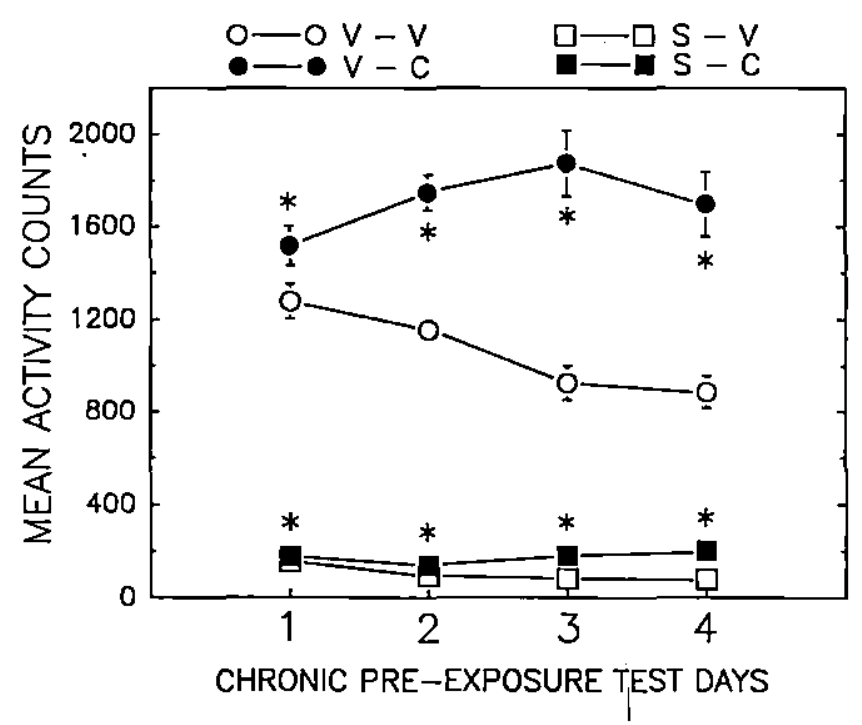

FIG. 3. Mean activity counts ( \pm SEM) per 20 -min session across the 4 preexposure days for groups of rats injected daily with either vehicle (V) or $0.5 \mathrm{mg} / \mathrm{kg} \mathrm{SCH} 23390$ (S) followed by either vehicle or 15 $\mathrm{mg} / \mathrm{kg}$ cocaine (C). ${ }^{*} p<0.05$ compared to $\mathrm{V}-\mathrm{V}$ group. 
$23390 \times$ Cocaine $\times$ Session interaction: $F(3,168)=7.20, p$ $<0.0001$ ].

Cocaine challenge test. The mean activity counts for the four preexposure groups following a challenge injection of cocaine are shown in Fig. 4. Although the main effect of cocaine did not reach significance $[F(1,56)=3.60, p<$ 0.06 , the SCH $23390 \times$ Cocaine interaction was significant $[F(1,56)=6.11, p<0.02]$. Analysis of this interaction indicated that groups of rats preexposed to cocaine and/or $\mathrm{SCH}$ 23390 were significantly more active following a cocaine challenge injection than rats previously treated with only vehicle [ $p$ 's $<0.05$ in each case]. The activity of these three preexposed groups (i.e., vehicle-cocaine, SCH 23390-vehicle, and SCH 23390-cocaine), however, did not differ significantly following the cocaine challenge injection [ $p$ 's $>0.05$ in each case]. That is, rats preexposed to SCH 23390 and cocaine were as active following the cocaine challenge injection as the rats preexposed only to cocaine, and like haloperidol, preexposure to SCH 23390 alone resulted in an increased locomotor response to cocaine.

\section{DISCUSSION}

Consistent with previous research, cocaine produced a greater increase in locomotor activity compared to vehicle injections, with repeated treatment [e.g., $(12,18,19)]$. Moreover, the acute activating effects of cocaine over days were similarly attenuated by the coadministration of either haloperidol or $\mathrm{SCH} 23390$. This finding is also consistent with previous research [e.g., $(3,7,21)$ ], which suggests that the expression of various dopamine agonist-induced behavioral effects requires the concomitant stimulation of both dopamine $D_{1}$ and $D_{2}$ receptors.

Although both dopamine antagonists blocked the acute locomotor-activating effects of cocaine, only haloperidol prevented the development of behavioral sensitization. This finding is consistent with previous work which indicates that

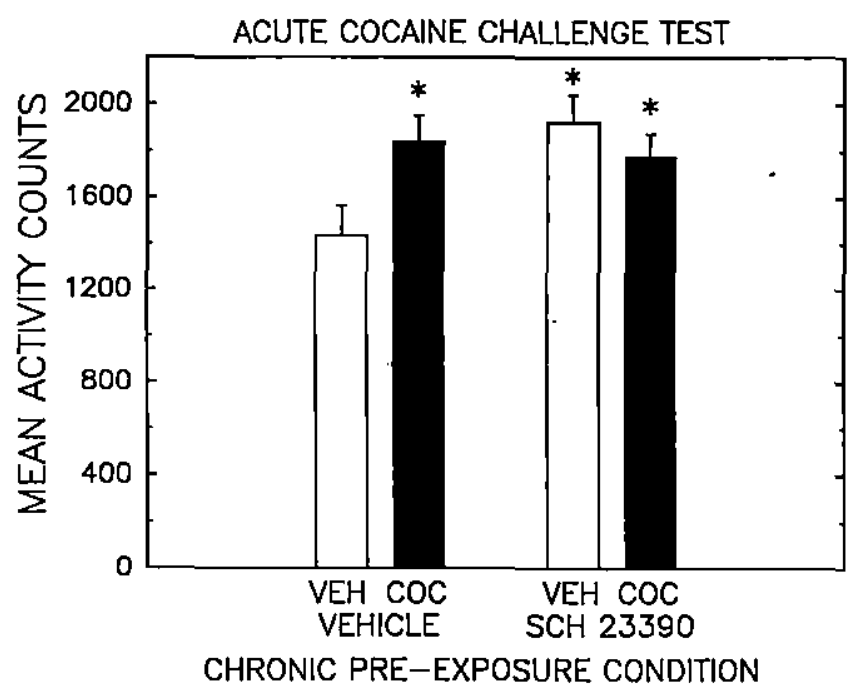

FIG. 4. Mean activity counts ( \pm SEM) per 20-min session following a challenge injection of cocaine for groups of rats previously treated daily for 4 days with vehicle or $0.5 \mathrm{mg} / \mathrm{kg} \mathrm{SCH} 23390$ and either vehicle (VEH) or $15 \mathrm{mg} / \mathrm{kg}$ cocaine (COC). $* p<0.05$ compared to VEHICLE-VEH group. coadministration of a relatively high dose of haloperidol $(0.5$ $\mathrm{mg} / \mathrm{kg}$ ) blocks the development of sensitization to a single high dose $(40 \mathrm{mg} / \mathrm{kg}$ ) of cocaine (35). Similarly, haloperidol also blocks the development of sensitization to repeated apomorphine treatments (20). As noted previously, the coadministration of more selective dopamine $\mathrm{D}_{2}$-type antagonists does not prevent the development of sensitization to cocaine (16, 19), amphetamine $(7,30,34)$, or apomorphine (21). Likewise, selective dopamine $D_{1}$-type antagonists are ineffective in blocking cocaine-induced behavioral sensitization (Experiment 2) $(16,19)$. Taken together, these findings suggest that the prevention of cocaine-induced behavioral sensitization may require the blockade of both dopamine $D_{1}$ - and $D_{2}$-type receptors.

It should be noted, however, that the neurochemical effects of cocaine and haloperidol are not limited to dopamine systems. Cocaine, for example, blocks neuronal reuptake of serotonin and norepinephrine as well as dopamine (8). Moreover, the acute locomotor-activating effects of cocaine are blocked by adrenergic, serotonergic, and $\sigma$-receptor antagonists $(2,31$, 37 , and repeated cocaine treatments produce alterations in other neurochemical systems besides dopamine $(6,17,33)$. Likewise, in addition to dopamine receptors, haloperidol has been reported to bind to both serotonin and sigma sites $(23,26)$. Thus, it is possible that the ability of high doses of haloperidol to block the development of cocaine-induced behavioral sensitization may be related to its nondopaminergic effects or to some combination of dopaminergic and nondopaminergic effects.

Also, it might be argued that the effectiveness of haloperidol in blocking the development of behavioral sensitization to cocaine, compared to other dopamine antagonists, may be related to its rather long half-life. In rats, the brain tissue half-life of haloperidol has been reported to be approximately $5 \mathrm{~h}(5)$. Because the cocaine challenge test was conducted only $24 \mathrm{~h}$ following the last the haloperidol treatment, a small amount of haloperidol may have been present, thereby reducing the locomotor-activating effects of cocaine. If this latter explanation were correct, however, the cocaine-induced activity increase observed in rats previously treated with haloperidol and vehicle for 4 days would also have been significantly reduced. As noted previously, the cocaine-induced activity of these haloperidol-treated rats did not differ significantly from that of rats previously treated with only cocaine (cf., Fig. 2). Thus, drug accumulation would not appear to account for the effectiveness of haloperidol in preventing the development of behavioral sensitization to cocaine.

Another intriguing, yet complicating, finding of the present study is that brief treatments (i.e., 4 days) with relatively high doses of either haloperidol or SCH 23390 enhanced the locomotor-activating effects of a subsequent cocaine challenge injection. As noted earlier, we observed a similar tendency after seven daily injections of sulpiride $(100 \mathrm{mg} / \mathrm{kg})$ or a lower dose of SCH $23390(0.30 \mathrm{mg} / \mathrm{kg})$ in a previous study with rats (19); and Kuribara and Uchihashi (16) reported that coadministration of SCH 23390 or YM-09151-2 with cocaine increases subsequent sensitivity to cocaine in mice. Consistent with these antagonist-induced changes in cocaine sensitivity, it has recently been reported that four daily treatments with the selective dopamine $D_{1}$-type agonist A-77636 decreases subsequent sensitivity to the locomotor-activating effects of cocaine (1). Moreover, repeated treatment (5 days) with the mixed dopamine antagonist cis-(Z)-flupentixol has recently been reported to increase subsequent sensitivity to cocaine in a selfadministration paradigm (24). Thus, brief antagonist treat- 
ments appear to enhance sensitivity to both the locomotor and rewarding effects of cocaine.

Although this antagonist-induced increase in cocaine sensitivity is interesting, it complicates the interpretation of the sensitization results. For example, in Experiment 2, rats preexposed to SCH 23390 and cocaine did not differ in activity from those pretreated only with cocaine on the cocaine challenge test. This suggests that SCH 23390 did not block the development of sensitization to cocaine. However, the SCH 23390-cocaine-pretreated rats also did not differ in activity from rats previously treated with only SCH 23390 on this cocaine challenge test. Because cocaine pretreatment did not add to the effect of SCH 23390 pretreatment, it might be argued that SCH 23390 did block cocaine-induced sensitization. Thus, it is possible that any attenuation of sensitization to cocaine resulting from the coadministration of selective antagonists might be masked by the antagonist-induced increase in cocaine sensitivity. Clearly, additional information concerning the mechanisms mediating this brief antagonistinduced increase in cocaine sensitivity is needed before an unambiguous interpretation is possible. Although haloperidol pretreatments also increased subsequent sensitivity to cocaine, rats pretreated with haloperidol and cocaine did not differ after the cocaine challenge injection from rats pretreated with only vehicle for 4 days. Thus, haloperidol clearly blocked the development of sensitization.

In conclusion, the present results indicate that brief pretreatments with either haloperidol or SCH 23390 increase subsequent sensitivity to cocaine. Further, the results indicate that high doses of haloperidol, but not SCH 23390, block the development of behavioral sensitization to cocaine. These findings, together with previous research, suggest that cocaineinduced behavioral sensitization may be mediated by the repeated stimulation of either dopamine receptor subtype alone. Moreover, because sensitization to amphetamine and apomorphine, but not cocaine, is prevented by selective dopamine $D_{1}$-type antagonists $[e . g$., $(7,19,21,34)]$, these results suggest that the development of sensitization to these three dopamine agonists may be mediated by different neurochemical mechanisms.

\section{ACK'NOWLEDGEMENTS}

This research was supported in part by grants from the NSF/ Kentucky EPSCoR Committee, Morehead State University, and USPHS Grant DA 09687. The authors are grateful to Karen Lim, Carmen Perkins, and Tamara Hart for their assistance in behavioral testing.

\section{REFERENCES}

1. Asin, K. E.; Nikkel, A. L.; Wirtshafter, D. Repeated $D_{1}$-receptor agonist treatment blocks cocaine-induced locomotor activity and c-fos expression. Brain Res. 637:342-344; 1994.

2. Berthold, C. W.; Gonzales, R. A.; Moerschbaecher, J. M. Prazosin attenuates the effects of cocaine on motor activity but not on schedule-controlled behavior in the rat. Pharmacol. Biochem. Behav. 43:111-115; 1992.

3. Braun, A. R.; Chase, T. N. Obligatory $D_{1}-D_{2}$-receptor coactivation and the generation of dopamine agonist related behaviors. Eur. J. Pharmacol. 131:301-306; 1986.

4. Burger, L. Y.; Martin-Iverson, M. T. Increased occupancy of $D_{1-}$ and $D_{2}$-dopamine receptors accompanies cocaine-induced behavioral sensitization. Brain Res. 639:228-232; 1994.

5. Cohen, B. M; Herschel, M.; Miller, E.; Mayberg, H.; Baldessarini, R. J. Radioreceptor assay of haloperidol tissue levels in the rat. Neuropharmacology 19:663-668; 1980.

6. Cunningham, K. A.; Paris, J. M.; Goeders, N. E. Chronic cocaine enhances serotonin autoregulation and serotonin uptake binding. Synapse 11:112-123; 1992.

7. Drew, K. L.; Glick, S. D. Role of $D_{1}$ - and $D_{2}$-receptor stimulation in sensitization to amphetamine-induced circling behavior and in expression and extinction of the Pavlovian conditioned response. Psychopharmacology 101:465-471; 1990.

8. Essman, W. D.; Singh, A.; Lucki, I. Serotonergic properties of cocaine: Effects on a $5-\mathrm{HT}_{2}$ receptor-mediated behavior and on extracellular concentrations of serotonin and dopamine. Pharmacol. Biochem. Behav. 49:107-113; 1994.

9. Fontana, D.; Post, R. M.; Weiss, S. R. B.; Pert, A. The role of $D_{1}$ - and $D_{2}$-dopamine receptors in the acquisition and expression of cocaine-induced conditioned increases in locomotor behavior. Behav. Pharmacol. 4:375-387; 1993.

10. Henry, D. J.; White, F. J. Repeated cocaine administration causes persistent enhancement of $D_{1}$-dopamine receptor sensitivity within the rat nucleus accumbens. J. Pharmacol. Exp. Ther. 258:882-890; 1991 .

11. Henry, D. J.; White, F. J. Electrophysiological correlates of psychomotor stimulant-induced sensitization. Ann. NY Acad. Sci. 654:88-100; 1992.

12. Kalivas, P. W.; Duffy, P.; DuMars, L. A.; Skinner, C. Behavioral and neurochemical effects of acute and daily cocaine administration in rats. J. Pharmacol. Exp. Ther. 245:485-492; 1988.
13. Kalivas, P. W.; Stewart, J. Dopamine transmission in the initiation and expression of drug- and stress-induced sensitization of motor activity. Brain Res. Rev. 16:223-244; 1991.

14. Kalivas, P. W.; Weber, B. Amphetamine injection into the ventral mesencephalon sensitizes rats to peripheral amphetamine and cocaine. J. Pharmacol. Exp. Ther. 245:1095-1101; 1988.

15. Kiyatkin, E. A. Enhanced locomotor reactivity to apomorphine following repeated cocaine treatment. Pharmacol. Biochem. Behav. 49:247-251; 1994.

16. Kuribara, H.; Uchihashi, Y. Dopamine antagonists can inhibit methamphetamine sensitization, but not cocaine sensitization, when assessed by ambulatory activity in mice. J. Pharm. Pharmacol. 45:1042-1045; 1993.

17. Levy, A. D.; Li, Q.; Sanz, M. C. A.; Rittenhouse, P. A.; Brownfield, M. S.; Van de Kar, L. D. Repeated cocaine modifies the neuroendocrine response to the $5-\mathrm{HT}_{1 \mathrm{c}} / 5-\mathrm{HT}_{2}$ receptor agonist DOI. Eur. J. Pharmacol. 221:121-127; 1992.

18. Martin-Iverson, M. T.; Reimer, A. R. Effects of nimodipine and/ or haloperidol on the expression of conditioned locomotion and sensitization to cocaine in rats. Psychopharmacology 114:315320; 1994.

19. Mattingly, B. A.; Hart, T. C.; Lim, K.; Perkins, C. Selective antagonism of dopamine $D_{1}$ - and $D_{2}$-receptors does not block the development of behavioral sensitization to cocaine. Psychopharmacology 114:239-242; 1994.

20. Mattingly, B. A.; Rowlett, J. K. Effects of repeated apomorphine and haloperidol treatments on subsequent behavioral sensitivity to apomorphine. Pharmacol. Biochem. Behav. 34:345-347; 1989.

21. Mattingly, B. A.; Rowlett, J. K.; Graff, J. T.; Hatton, B. J. Effects of selective $D_{1}$-and $D_{2}$-dopamine antagonists on the development of behavioral sensitization to apomorphine. Psychopharmacology 105:501-507; 1991 .

22. Mattingly, B. A.; Rowlett, J. K.; Lovell, G. Effects of daily SKF 38393, quinpirole, and SCH 23390 treatments on locomotor activity and subsequent sensitivity to apomorphine. Psychopharmacology 110:320-326; 1993.

23. O'Dell, S. J.; La Hoste, G. J; Widmark, C. B.; Shapiro, R. M.; Potkin, S. G.; Marshall, J. F. Chronic treatment with clozapine or haloperidol differentially regulates dopamine and serotonin receptors in rat brain. Synapse 6:14-153; 1990 .

24. Peltier, P. L.; Emmett-Oglesby, M. W. Sensitization to cocaine 
self-administration following chronic cis (Z)-flupentixol. Soc. Neurosci. Abstr. 20:1631; 1994.

25. Peris, J.; Zahniser, N. R. Persistent augmented dopamine release after acute cocaine requires dopamine receptor activation. Pharmacol. Biochem. Behav. 32:71-76; 1989.

26. Quiron, R.; Bowen, W. D.; Itzhak, Y.; Junien, J. L.; Musacchio, J. M.; Rothaman, R. B.; Su, T. P.; Tam, S. W.; Taylor, D. P. A proposal for the classification of sigma binding sites. Trends Pharmacol. Sci. 13:85-86; 1992.

27. Reimer, A. R.; Martin-Iverson, M. T. Nimodipine and haloperidol attenuate behavioural sensitization to cocaine but only nimodipine blocks the establishment of conditioned locomotion induced by cocaine. Psychopharmacology 113:404-410; 1994.

28. Robinson, T. E.; Becker, J. B. Enduring changes in brain and behavior produced by chronic amphetamine administration: A review and evaluation of animal models of amphetamine psychosis. Brain Res. Rev. 11:157-198; 1986.

29. Stewart, J.; Badiani, A. Tolerance and sensitization to the behavioral effects of drugs. Behav. Pharmacol. 4:289-312; 1993.

30. Stewart, J.; Vezina, P. Microinjections of Sch-23390 into the ventral tegmental area and substantia nigra pars reticulata attenuate the development of sensitization to the locomotor activating effects of systemic amphetamine. Brain Res. 495:401-416; 1989.

31. Svingos, A. L.; Hitemann, R. 5-HT, receptor antagonists block cocaine-induced locomotion via a PCPA-sensitive mechanism. Pharmacol. Biochem. Behav. 43:871-879; 1992.

32. Tella, S. R. Differential blockade of chronic vs. acute effects of intravenous cocaine by dopamine receptor antagonists. Pharmacol. Biochem. Behav. 48:151-159; 1994.

33. Unterwald, E. M.; Rubenfeld, J. M.; Kreek, M. J. Repeated cocaine administration upregulates $k$ and $u$, but not $\delta$, opioid receptors. Neuroreport 5:1613-1616; 1994.

34. Vezina, P.; Stewart, J. The effect of dopamine receptor blockade on the development of sensitization to the locomotor activating effects of amphetamine and morphine. Brain Res. 499:108-120; 1989.

35. Weiss, R. B.; Post, R. M.; Pert, A.; Woodward, R.; Murman, D. Context-dependent cocaine sensitization: Differential effect of haloperidol on development vs. expression. Pharmacol. Biochem. Behav. 34:655-661; 1989.

36. Wise, R. A.; Carlezon, W. A. Attenuation of the locomotorsensitizing effects of the $\mathrm{D}_{2}$-dopamine agonist bromocryptine by either the $\mathrm{D}_{1}$-antagonist $\mathrm{SCH} \mathbf{2 3 3 9 0}$ or the $\mathrm{D}_{2}$-antagonist raclopride. Synapse 17:155-159; 1994.

37. Witkin, J. M.; Terry, P.; Menkel, M.; Hickory, P.; Pontecorvo, M.; Ferkany, J.; Katz, J. L. Effects of the selective sigma receptor ligand, 6-[6-(4-hydroxypiperidinyl)hexoxy]-3-methylflavone (NPC 16377), on behavioral and toxic effects of cocaine. J. Pharmacol. Exp. Ther. 266:473-482; 1993. 